\title{
PERANCANGAN PEMBANGKIT LISTRIK TENAGA ANGIN DENGAN TURBIN VENTILATOR SEBAGAI PENGGERAK GENERATOR
}

\author{
Made Padmika $^{1}$, I Made Satriya Wibawa ${ }^{1}$, Ni Luh Putu Trisnawati ${ }^{1}$ \\ ${ }^{1}$ Jurusan Fisika, Fakultas Matematika dan Ilmu Pengetahuan Alam, \\ Universitas Udayana, Kampus Bukit Jimbaran, Badung, Bali Indonesia 80361 \\ *Email: deknoppaper@gmail.com
}

\begin{abstract}
Abstrak Telah dibuat prototype pembangkit listrik tenaga angin dengan menggunakan turbin ventilator sebagai penggerak generator. Pembangkit listrik ini memanfaatkan kecepatan angin sebagai penggeraknya. Listrik yang dihasilkan berupa tegangan DC antara 0 volt sampai dengan 7,46 volt. Output dari generator diolah dengan menggunakan modil MT3608. Modul MT3608 digunakan untuk menstabilkan dan menaikkan tegangan yang dipasang di input dan output dari rangkaian charging. Untuk pengujian alat, kecepatan angin yang dipakai dari kecepatan angin $0 \mathrm{~m} / \mathrm{s}$ sampai dengan $6 \mathrm{~m} / \mathrm{s}$. Keluaran maksimal alat ini dengan kecepatan angin $6 \mathrm{~m} / \mathrm{s}$ adalah 7,46 volt.
\end{abstract}

Kata Kunci: angin, turbin ventilator, listrik.

Abstrack A prototype of a wind power plant had been created using a ventilator as a generator spiner. This power plant utilizes wind speed as its propulsion. Electricity generated in the DC voltage form between 0 volts up to 7.46 volts. The MT3608 module is used to stabilize and raise the voltage installed in the input and output of the charging circuit. For instrument testing, the wind speed on $0 \mathrm{~m} / \mathrm{s}$ up to $6 \mathrm{~m} / \mathrm{s}$ interval used. Maximum output of this tool with a wind speed of $6 \mathrm{~m} / \mathrm{s}$ is 7.46 volts.

Keywords: wind, ventilator turbine, electricity.

\section{PENDAHULUAN}

Krisis penyediaan listrik dibeberapa daerah mengakibatkan efek tidak menguntungkan bagi pertumbuhan ekonomi Indonesia sebab pertumbuhan ekonomi masyarakan menyebabkan permintaan akan tenaga listrik meningkat pula. Untuk mengatasi hal tersebut, pemerintah berupaya membuat pembangkit listrik alternatif memanfaatkan sumber daya yang bisa diperbaharui seperti angin, cahaya matahari dan lain-lain [1].

Lembaga Antariksa dan Penerbangan Nasional (Lapan) pernah melakukan survei energi angin di dua puluh daerah di Indonesia. Kecepatan rata-rata angin di Indonesia pertahun sekitar 2 sampai $6 \mathrm{~m} / \mathrm{s}$. Beberapa daerah di Indonesia bagian timur memiliki kecepatan angin rata-rata $5 \mathrm{~m} / \mathrm{s}$.

Angin merupakan energi yang dapat diperbaharui karena ketersediaannya tidak terbatas di alam. Tidak seperti batu bara dan minyak bumi yang ketersediaannya terbatas.
Angin pada dasarnya dibangkitkan dengan menggunakan kincir angin. Cara ini telah dikenal sejak beberapa abad yang lalu seperti di Belanda yang dikenal sebagai negara kincir angin. Pembangkit listrik yang menggunakan energi tidak terbaharukan seperti minyak bumi atau batu bara banyak digunakan diberbagai belahan negara untuk memproduksi listrik dalam skala besar. Namun karena merupakan energi yang tak terbarukan maka seiring berjalannya waktu sumber tersebut akan berkurang dan pada waktunya akan habis. Oleh karena itu, diperlukan pembangkit listrik energi alternatif seperti energi angin untuk menggantikan energi fosil yang semakin berkurang. Dalam kaitannya dengan pemanfaatan energi angin penulis telah membuat prototipe perancangan pembangkit listrik tenaga angin dengan turbin ventilator sebagai penggerak generator. 


\section{TINJAUAN PUSTAKA}

\subsection{Turbin Ventilator}

Turbin ventilator merupakan turbin angin dengan sumbu putar vertikal yang memiliki fungsi sebagai turbin angin dan juga kipas hisap. Turbin ventilator menggunakan energi angin sebagai pengganti kipas ventilasi bertenaga listrik [2]. Gambar 1 adalah gambar turbin ventilator.

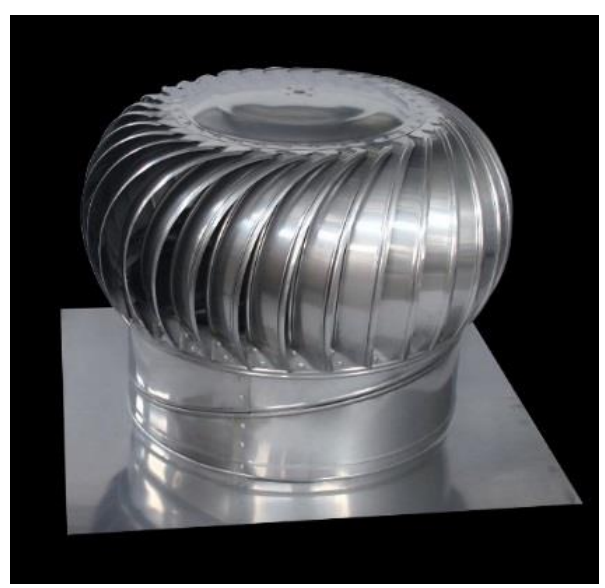

Gambar 1. Turbin ventilator.

\subsection{Generator}

Generator merupakan salah satu alat atau perangkat mesin yang menghasilkan energi listrik dari sumber energi mekanik atau gerak melalui proses induksi elektromagnetik [3]. Generator ada 2 jenis yaitu generator AC dan generator DC. Generator AC adalah generator yang menghasilkan listrik dengan tegangan bolakbalik, dan Generator DC adalah generator yang menghasilkan listrik searah.

\subsection{Aki}

Accumulator atau sering disebut dengan aki merupakan salah satu komponen yang ada pada kendaraan bermotor seperti mobil dan motor. Yogopranoto, (2012) menjelaskan bahwa aki mengubah energi kimia dan menjadikannya energi listrik. Berdasarkan elemen yang digunakan untuk aki, dapat dibedakan menjadi dua yaitu dengan bahan berupa larutan atau cairn yang biasa disebut aki basah, dan ada yang berupa plat yang biasa disebut aki kering [4]. Gambar 2 adalah gambar sel aki.

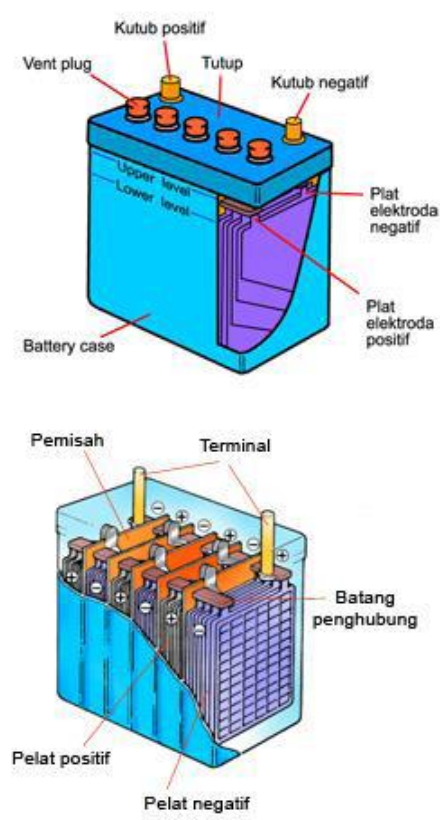

Gambar 2. Sel Aki.

\subsection{Baterai Charging}

Rangkaian yang digunakan untuk melakukan proses Battery Charging disebut Charger, yaitu alat yang bisa memberikan muatan terhadap suatu komponen yang dapat menyimpan muatan listrik. Battery charging beroperasi pada sistem arus konstan atau potensial konstan.

\subsection{Roda Gigi}

Fungsi roda gigi yaitu untuk mentransmisikan atau menyalurkan daya besar dan putaran yang tepat. Roda gigi memiliki gigi di sekelilingnya, sehingga penerusan daya dilakukan oleh gigi-gigi kedua roda yang saling berkait dan bersentuhan [5].

\section{METODE PENELITIAN}

\subsection{Alat dan Bahan}

Alat dan bahan yang digunakan pada penelitian ini adalah kapasitor $4700 \mathrm{uF}$ $125 \mathrm{~V}$, Led hijau dan led merah, resistor $1 \mathrm{k} \Omega$, trimpot $1 \mathrm{k} \Omega$, diode $1 \mathrm{~N} 4007$, relay 6 V, IC 7808, saklar, aki 12 volt dengan merek Yuasa, diode Zener, IC LM324, transistor $\mathrm{BC} 548$, turbin ventilator yang dimodifikasi, generator DC yang dapat menghasilkan listrik, inverter, solder, timah, pinset, gunting kuku, anemometer digital, kabel. 


\subsection{Diagram Blok Alat}

Diagram blok dari pembangkit listrik tenaga angin dengan turbin ventilator dapat dilihat pada Gambar 4.

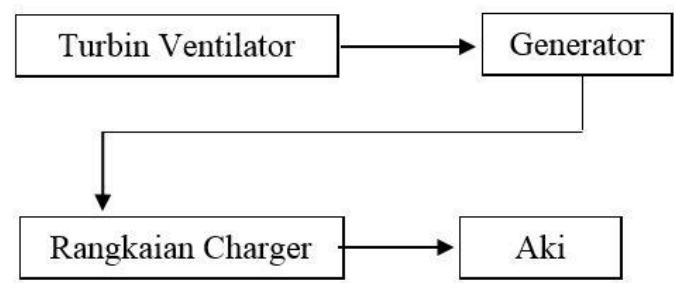

Gambar 4. Diagram blok alat.

Pada perancangan ini terdapat 3 alat utama guna menghasilkan listrik diantaranya turbin ventilator, dinamo, dan rangkaian charger yang digunakan untuk mengisi sebuah aki 12 volt.

\subsection{Rangkaian Charger}

Rangkaian charger digunakan utuk melakukan proses charging baterai atau aki dengan aman, sehingga tidak akan merusak sel baterai atau aki ketika aki telah penuh. Skema dari rangkaian charger diperlihatkan pada Gambar 5.

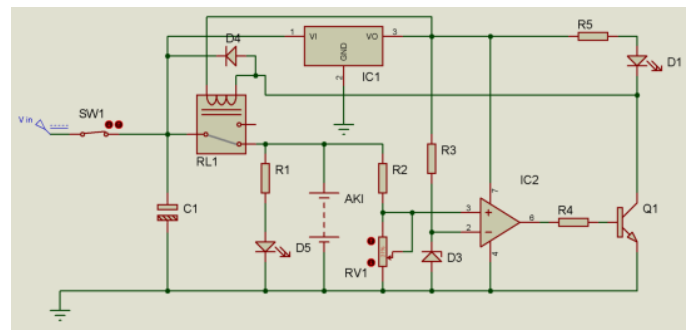

Gambar 5. Rangkaian Charger.

Rangkaian charger ini berfungsi untuk menghentikan proses charging secara otomatis ketika baterai atau aki sudah terisi penuh. Diagram alur dari proses charging ini diperlihatkan pada Gambar 6 .

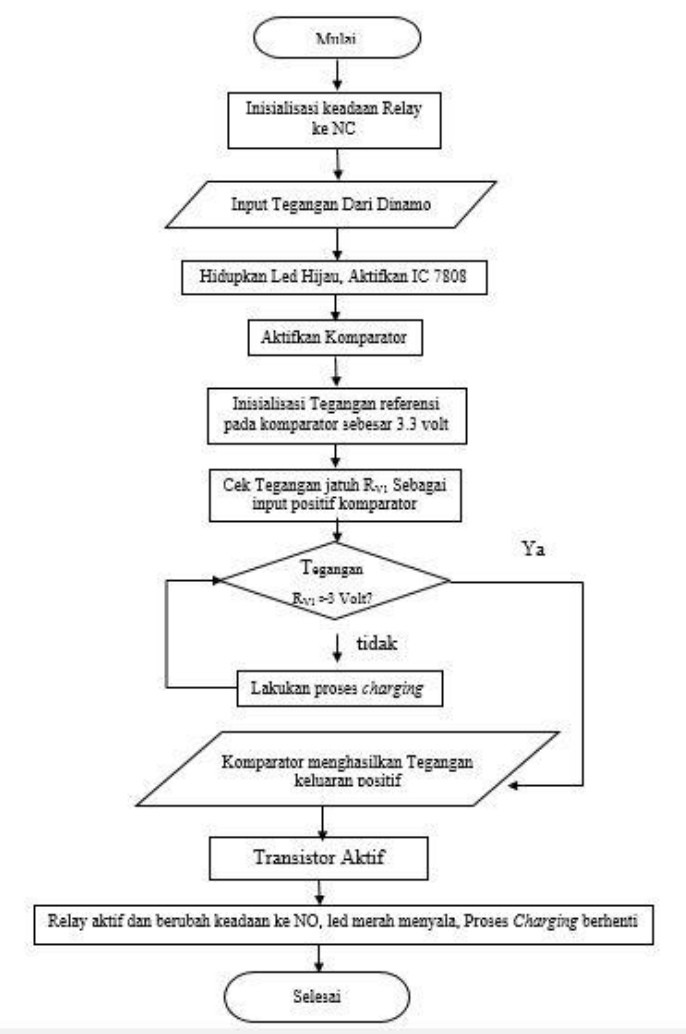

Gambar 6. Diagram alur rangkaian charging.

\section{HASIL DAN PEMBAHASAN}

\subsection{Hasil}

Hasil yang diperoleh dari penelitian ini adalah alat pembangkit listrik tenaga angin dengan turbin ventilator sebagai penggerak generator seperti ditunjukkan Gambar 7.

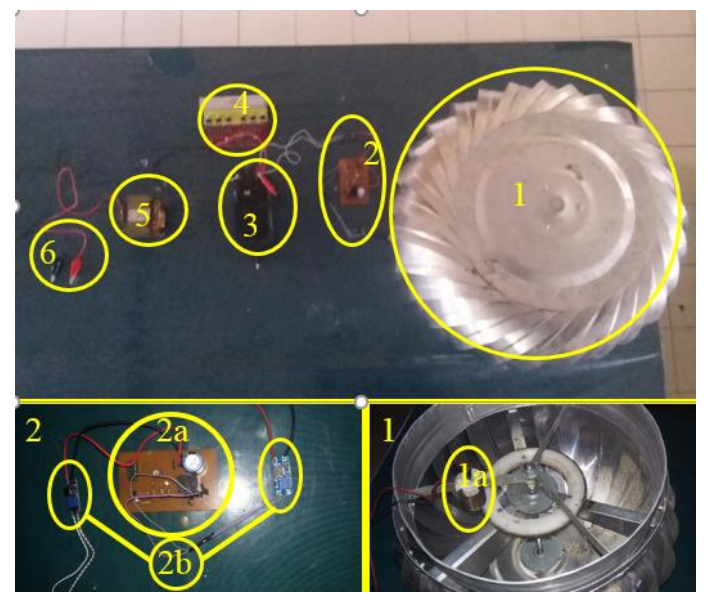

Gambar 7. Prototype pembangkit listrik tenaga angin dengan turbin ventilator.

Penjelasan singkat dari fungsi masingmasing bagian pokok alat pembangkit listrik tenaga angin dengan turbin ventilator 
sebagai penggerak generator ditunjukan pada Gambar 7 yaitu sebagai berikut.
1. Turbin Ventilator
1a. Generator
2a. Rangkaian Charging
2b. Step up DC to DC
3. Aki 12 volt
4. Inverter $D C$ to $A C$
5. Transformator
6. Output

\subsection{Pembahasan}

Turbin ventilator dapat berputar karena faktor kecepatan angin dan perbedaan tekanan udara. Hembusan angin yang mengenai sirip dari turbin ventilator dapat mengakibatkan berputarnya turbin ventilator.

Pengkombinasian jumlah roda gigi pada turbin ventilator dengan yang ada pada ujung generator diperlukan untuk mendapatkan jumlah putaran yang berkali lipat lebih banyak antara putaran generator dengan putaran turbin ventilator. Perbandingan roda gigi yang dipakai didalam turbin dengan roda gigi pada generator adalah 125 berbanding dengan 10 .

Generator mengubah energi mekanik ke energi listrik atau dalam hal ini menghasilkan tegangan listrik DC. Tegangan yang dihasilkan generator tidak stabil, hal ini karenakan putaran generator yang tidak stabil akibat dari bentuk tudung turbin yang tidak bulat sempurna. Untuk menstabilkan keluaran dari generator, digunakan modul MT3608 yang dapat menstabilkan tegangan menjadi maksimal 28 volt dengan tegangan input minimal 2 volt.

Tegangan yang sudah stabil selanjutnya akan menjadi input untuk rangkaian charging. Rangkaian charging pada alat ini menggunakan relay yang fungsinya adalah sebagai saklar otomatis. Setelah melewati rangkaian charging, selanjutnya listrik disimpan dalam aki.

\subsection{Data Pengukuran Tegangan dan Arus}

Pengukuran tegangan dan arus rangkaian ini menggunakan kipas angin sebagai penghasil sumber angin, anemometer digital sebagai alat ukur kecepatan anginnya, dan avometer untuk mengukur tegangan dan arus yang dihasilkan oleh generator. Berikut data kecepatan angin.

Tabel 1. Kecepatan angin dengan tegangan diberi beban (resistor + led)

\begin{tabular}{cccccccc}
\hline \multirow{2}{*}{ No } & Kec Angin & \multicolumn{5}{c}{ Tegangan V pada Beban $\mathrm{B}_{\mathrm{i}}($ volt $)$} & Tegangan rata-rata \\
\cline { 3 - 6 } & $(\mathrm{m} / \mathrm{s}) \pm 0.1$ & $\mathrm{~B}_{1}$ & $\mathrm{~B}_{2}$ & $\mathrm{~B}_{3}$ & $\mathrm{~B}_{4}$ & $\mathrm{~B}_{5}$ & $(\mathrm{~V})$ \\
\hline 1 & 0 & 0,00 & 0,00 & 0,00 & 0,00 & 0,00 & 0,00 \\
2 & 1 & 0,00 & 0,00 & 0,00 & 0,00 & 0,00 & 0,00 \\
3 & 2 & 1,22 & 1,30 & 1,41 & 1,32 & 1,36 & 1,32 \\
4 & 3 & 4,56 & 4,88 & 4,40 & 4,39 & 4,46 & 4,54 \\
5 & 4 & 5,64 & 5,62 & 5,49 & 5,52 & 5,43 & 5.54 \\
6 & 5 & 7,41 & 7,23 & 7,27 & 7,34 & 7,16 & 7,28 \\
7 & 6 & 7,60 & 7,51 & 7,40 & 7,49 & 7,31 & 7,46 \\
\hline
\end{tabular}

terhadap tegangan dan arus menggunakan resistor $465 \mathrm{Ohm}$ dan Led merah yang dihasilkan generator dengan pencarian data masing-masing dilakukan sebanyak lima kali. Tabel 1 adalah tabel kecepatan angin dengan tegangan yang diberi beban (resistor + led).

Dari Tabel 1 dapat dibuat grafik hubugan antara tegangan dan kecepatan angin seperti pada Gambar 8. Dari Gambar 8 terlihat antara $0 \mathrm{~m} / \mathrm{s}$ sampai dengan $1 \mathrm{~m} / \mathrm{s}$ tidak ada tegangan yang keluar. Hal ini terjadi karena tudung turbin tidak berputar pada kecepatan tersebut. Generator mulai ada keluaran saat kecepatan angin lebih dari $1 \mathrm{~m} / \mathrm{s}$ dan meningkat terus sampai pada kecepatan $6 \mathrm{~m} / \mathrm{s}$. Namun saat kecepatan angin antara $5 \mathrm{~m} / \mathrm{s}$ dan $6 \mathrm{~m} / \mathrm{s}$ peningkatan tegangan yang dihasilkan oleh generator menurun dibandingkan dengan saat awal. 


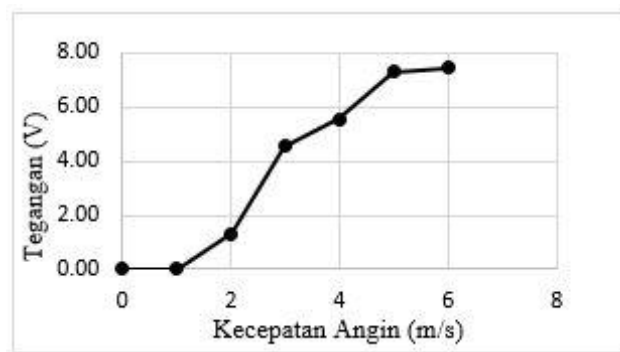

Tabel kecepatan angin dengan arus ditampilkan pada Tabel 2. Dari Tabel 2 dapat dibuat grafik kecepatan angin dengan arus seperti pada Gambar 9.

Gambar 8. Grafik hubungan antar tegangan dan kecepatan angin.

Tabel 2. Kecepatan angin dengan arus diberi beban (resistor + led).

\begin{tabular}{cccccccc}
\hline \multirow{2}{*}{ No } & Kec Angin & \multicolumn{5}{c}{ Arus I dengan beban $\mathrm{B}_{\mathrm{i}}(\mathrm{mA})$} & Arus ata-rata \\
\cline { 3 - 7 } & $(\mathrm{m} / \mathrm{s}) \pm 0,1$ & $\mathrm{~B}_{1}$ & $\mathrm{~B}_{2}$ & $\mathrm{~B}_{3}$ & $\mathrm{~B}_{4}$ & $\mathrm{~B}_{5}$ & $(\mathrm{~mA})$ \\
\hline 1 & 0 & 0,00 & 0,00 & 0,00 & 0,00 & 0,00 & 0,00 \\
2 & 1 & 0,00 & 0,00 & 0,00 & 0,00 & 0,00 & 0,00 \\
3 & 2 & 0,24 & 0,11 & 0,20 & 0,35 & 0,19 & 0,22 \\
4 & 3 & 47,50 & 48,30 & 45,80 & 47,70 & 46,20 & 47,10 \\
5 & 4 & 64,70 & 63,80 & 62,60 & 63,40 & 62,70 & 63,44 \\
6 & 5 & 86,20 & 84,10 & 85,80 & 87,10 & 87,40 & 86,12 \\
7 & 6 & 134,60 & 127,10 & 126,70 & 120,10 & 124,00 & 126,50 \\
\hline
\end{tabular}

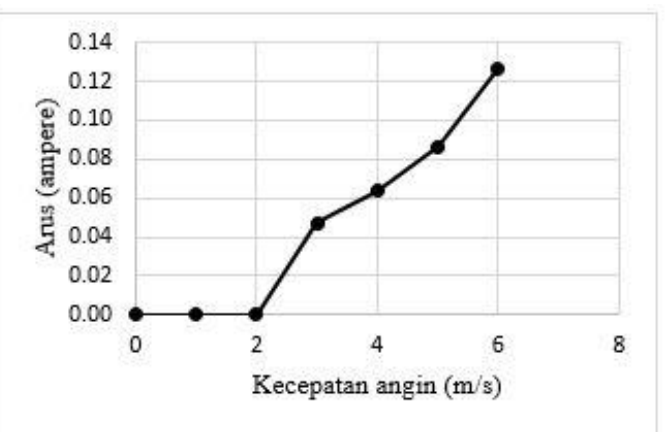

Gambar 9. Grafik hubungan antara kecepatan angin dengan arus.

Dari Gambar 9, generator mulai menghasilkan arus atau arus mulai terbaca pada Avometer saat kecepatan angin yang menghembuskan tudung turbin lebih besar dari $2 \mathrm{~m} / \mathrm{s}$. Maksimal arus yang dihasilkan oleh generator yaitu pada kecepatan angin 6 $\mathrm{m} / \mathrm{s}$ adalah $0,13 \mathrm{~A}$.

Data pengisian aki dengan menggunakan kecepatan angin $6 \mathrm{~m} / \mathrm{s}$ dan pencatatan data dilakukan dalam selang waktu 30 menit yang mana aki sudah memiliki tegangan awal 6,19 volt ditampilkan pada Tabel 3.
Tabel 3. Pengisian aki.

\begin{tabular}{cccc}
\hline No & $\begin{array}{c}\text { Kecepatan } \\
\text { angin }(\mathrm{m} / \mathrm{s})\end{array}$ & $\begin{array}{c}\text { Waktu } \\
\text { (menit) }\end{array}$ & $\begin{array}{c}\text { Tegangan } \\
\text { (volt) }\end{array}$ \\
\hline 1 & 6 & 0 & 6,19 \\
2 & 6 & 30 & 7,30 \\
3 & 6 & 60 & 7,88 \\
4 & 6 & 90 & 8,40 \\
5 & 6 & 120 & 8,82 \\
\hline
\end{tabular}

Dari Tabel 3 dapat dibuat grafik seperti pada Gambar 10.

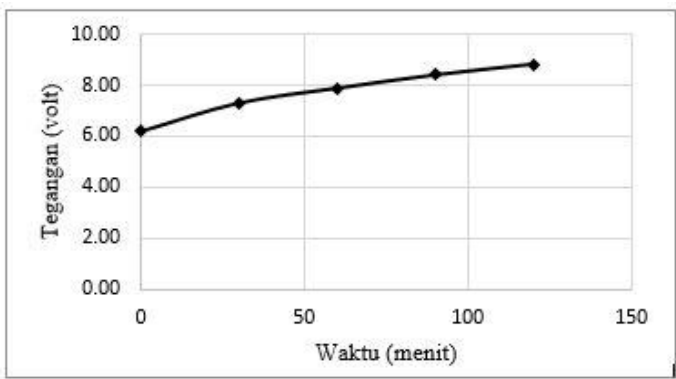

Gambar 10. Grafik pengisian aki.

Grafik pengisian aki dengan kecepatan angin $6 \mathrm{~m} / \mathrm{s}$ ditampilkan pada Gambar 10 Tegangan awal aki adalah 6,19 volt. Selama 120 menit proses charging, 
tegangan aki menjadi 8,82 volt atau meningkat sejumlah 2,63 volt. Pengisian aki pada menit-menit awal terlihat meningkat lebih tinggi dibandingkan dengan menit berikutnya. Hal ini dikarenakan aki yang sudah terisi, akan lebih sulit untuk diisi kembali.

\section{KESIMPULAN}

Dari hasil yang diperoleh dan pembahasan yang sudah disampaikan, telah dibuat prototype pembangkit listrik tenaga angin dengan turbin ventilator sebagai penggerak generak generator yang mampu berputar dengan kecepatan angin minimal 2 $\mathrm{m} / \mathrm{s}$. Listrik yang dihasilkan dengan kecepatan angin $6 \mathrm{~m} / \mathrm{s}$ adalah 7,46 volt. Semakin cepat kecepatan angin akan mengakibatkan tegangan maupun arus listrik yang dihasilkan semakin besar.

\section{DAFTAR PUSTAKA}

[1] Mahmudi, Wakid. Pengaruh Rasio panjang Dan Diameter Pipa Cerobong Turbine Ventilator Terhadap Unjuk Kerja Turbine Ventilator Sebagai Mikro Power Plant. Jurnal Teknik Mesin FTI Institut Tinggi Sepuluh November. 2010. Halaman 1 - 10.
[2] Ismail, M., Abdul Malek Abdul Rahman. Rooftop Turbine Ventilator: A Review and Update. Penang: School of Housing, Building \& Planing, Universiti Sains Malaysia. 2012.

[3] Budiman, A., dkk. Desain Generator Magnet Permanen untuk Sepeda Listrik, Jurnal Jurusan Teknik Elektro. Fakultas Teknik Universitas Muhammadiah Surakarta. 2012.

[4] Yogopranoto, D., dkk. Daur Ulang Timbal (Pb) Dari Aki Bekas Dengan Menggunakan Metode Redoks. Semarang: Jurusan Teknik Mesin Fakultas Teknik Universitas Diponegoro. 2012.

[5] Chan, Yefri. Teori Dasar Roda Gigi. Jakarta Jurnal Universitas dharma Persada, 2011. 